\title{
GAMBARAN KEJADIAN MEDICATION ERROR DI INSTALASI GAWAT DARURAT RSU ELIM RANTEPAO
}

\author{
Priskha Widiastuti $^{1)}$, Gayatri Citraningtyas ${ }^{\text {1) }}$, Jainer P.Siampa ${ }^{1)}$ \\ 1) Program Studi Farmasi FMIPA UNSRAT Manado, 95115
}

\begin{abstract}
Medication Error is an event that is detrimental to the patient due to errors in the administration of drugs during the handling of health personnel, which can actually be prevented. Data on incidents of medication errors at Elim Hospital, Rantepao in 2017 were 85 cases (0.085\% of the total 98,892 prescription sheets served). This study aims to determine the incidence and the percentage of medication errors during the prescribing and dispensing phase in the Emergency Installation of Elim Hospital ,Rantepao. This research is a descriptive analysis with prospective data collection. The results showed that medication errors which occurred at prescribing stage included no prescription doctor's name was 9.19\%, no medical record number was 6.13\%, no doctor's initial was 99.61\%, patient's name was not clear was $0.57 \%$, there was no patient age, was $6.89 \%$, no concentration / dosage was $2.68 \%$, no dosage form was $52.10 \%$, and no prescription date was $1.72 \%$. While medication errors at the dispensing stage include taking the drug was $0.38 \%$ and the lack of drug prepared was $0.19 \%$. Based on the results of the study, it can be concluded that the biggest occurrence of medication errors in Emergency Services at Elim Hospital, Rantepao was occurred in the prescribing phase.
\end{abstract}

Keywords: medication error, prescribing, dispensing, Emergency Installation

\begin{abstract}
ABSTRAK
Medication Error adalah kejadian yang merugikan pasien akibat kesalahan dalam pemberian obat selama penanganan tenaga kesehatan, yang sebetulnya dapat dicegah. Data insiden kejadian medication error RSU Elim Rantepao pada tahun 2017 yaitu sebanyak 85 kasus (0,085 \% dari total 98.892 lembar resep yang dilayani). Penelitian ini bertujuan menentukan kejadian dan persentase medication error pada fase prescribing dan dispensing di Instalasi Gawat Darurat RSU Elim Rantepao. Penelitian ini merupakan penelitian yang bersifat analisis deskriptif dengan pengumpulan data secara prospektif. Hasil penelitian menunjukkan bahwa medication error yang terjadi pada tahap prescribing meliputi tidak ada nama dokter penulis resep 9,19\%, tidak ada nomor rekam medik 6,13\%, tidak ada paraf dokter 99,61\%, nama pasien tidak jelas $0,57 \%$, tidak ada usia pasien $6,89 \%$, tidak ada konsentrasi/dosis sediaan $2,68 \%$, tidak ada bentuk sediaan 52,10 \%, dan tidak ada tanggal pembuatan resep 1,72\%. Sedangkan medication error pada tahap dispensing meliputi salah pengambilan obat $0,38 \%$ dan obat ada yang kurang $0,19 \%$. Berdasarkan hasil penelitian maka dapat disimpulkan bahwa kejadian medication error di Instalasi Gawat Darurat RSU Elim Rantepao terbesar yaitu terjadi pada fase prescribing.
\end{abstract}

Kata-kata kunci : medication error, prescribing, dispensing, Instalasi Gawat Darurat 


\section{PENDAHULUAN}

Keselamatan pasien didefinisikan sebagai suatu upaya untuk mencegah terjadinya bahaya atau cedera pada pasien selama proses pengobatan (Department Kesehatan RI, 2008). Secara umum keselamatan pasien meliputi pencegahan kesalahan dan mengeliminasi berbagai bahaya akibat kesalahan tersebut. Kesalahan dapat dilakukan oleh anggota tim kesehatan dan dapat terjadi setiap saat selama proses pelayanan kesehatan, khususnya dalam pengobatan pasien (Temasixeira, 2010).

Kesalahan pengobatan (Medication Error) adalah kejadian yang merugikan pasien akibat pemakaian obat selama dalam penanganan tenaga kesehatan, yang sebetulnya dapat dicegah. Berdasarkan Laporan Peta Nasional Insiden Keselamatan Pasien kesalahan dalam pemberian obat menduduki peringkat pertama $(24,8 \%)$ dari 10 besar insiden yang dilaporkan. Menurut Mashuda (2011), medication error digolongkan dalam tiga fase yaitu fase prescribing, dispensing, dan administration.

Medication error termasuk dalam salah satu penyebab error yang signifikan di Instalasi Gawat Darurat (IGD). Studi adverse drug event yang dilaporkan dalam database nasional menunjukkan bahwa medication error di IGD dua kali lipat dari insiden di rawat inap (Tajuddin et al., 2012). Studi yang dilakukan Patanwala (2010) menyatakan 178 medication error terjadi dari 194 pasien di instalasi gawat darurat. Insiden medication error yang dilaporkan di RSU Elim Rantepao yaitu sebanyak 85 kasus $(0,085 \%$ dari total 98.892 lembar resep yang dilayani) pada tahun 2017.
Gambaran kejadian medication error perlu diketahui agar dapat dilakukan pencegahan.

Tujuan penelitian ini untuk mengetahui gambaran kejadian serta jumlah persentase medication error pada fase prescribing dan dispensing di ruang IGD Rumah Sakit Umum Elim Rantepao.

\section{METODOLOGI PENELITIAN}

\section{Tempat dan Waktu Penelitian}

Penelitian ini dilakukan di ruang Instalasi Faarmasi RSU Elim Rantepao pada bulan Januari - Februari 2019.

\section{Jenis Penelitian}

Penelitian ini merupakan penelitian yang bersifat analisis deskriptif dengan pengumpulan data secara prospektif yang didasarkan pada data resep pasien IGD RSU Elim Rantepao periode Januari - Februari 2019.

\section{Populasi dan Sampel Penelitian}

Populasi dalam penelitian ini adalah seluruh resep pasien di Instalasi Gawat Darurat RSU Elim Rantepao pada bulan Januari - Februari 2019. Sampel yang dijadikan subjek penelitian ini adalah resep pasien di Instalasi Gawat Darurat yang memenuhi kriteria selama penelitian berlangsung. Sampel penelitian ini diambil dengan menggunakan metode purposive sampling dengan kriteria inklusi dan kriteria eksklusi yang disajikan dalam Tabel 1.

Tabel 1. Kriteria Inklusi dan Eksklusi

\begin{tabular}{ll}
\hline \multicolumn{1}{c}{ Kriteria Inklusi } & \multicolumn{2}{c}{ Kriteria Eksklusi } \\
\hline Resep masuk dari & Resep pasien IGD \\
dokter RSU Elim & yang tidak diambil/ \\
Rantepao & dibatalkan/meninggal \\
\hline Resep yang masuk & Resep pasien dengan \\
di depo IGD RSU & lama perawatan \\
Elim Rantepao & diatas satu hari \\
\hline
\end{tabular}




\section{Pengumpulan Data}

Data dikumpulkan dan dicatat dari pengamatan resep ruang IGD RSU Elim Rantepao. Setiap temuan Medication Error misalnya tulisan resep tidak terbaca, tidak ada nama dokter penulis resep, tidak ada nomor rekam medik, tidak ada paraf dokter, nama pasien tidak jelas, tidak ada usia, tidak ada konsentrasi/dosis sediaan, tidak ada jumlah obat, tidak ada aturan pakai, tidak ada bentuk sediaan, tidak ada tanggal pembuatan resep, salah pengambilan obat, salah menyerahkan obat pada pasien, pemberian etiket yang salah atau tidak lengkap, pemberian obat diluar instruksi, obat yang ada kurang, dan obat kadaluarsa/sudah rusak. Tabulasi data dalam bentuk persentase dari masing-masing bentuk kejadian Medication Error dengan menggunakan diagram batang.

\section{Analisis Data}

Analisis data dihitung dalam besaran persentase pada fase kejadian Medication Error. Menurut Sibagariang (2010), penentuan besarnya persentase sebagai berikut:

$$
P=\frac{f}{n} x 100 \%
$$

Keterangan:

$\mathrm{P}=$ Hasil Persentase

$\mathrm{f}=$ Frekuensi hasil (kejadian Medication Error)

$\mathrm{n}=$ Total seluruh presentasi hasil observasi

\section{HASIL DAN PEMBAHASAN}

\section{Hasil}

Penelitian prospektif ini memperoleh 1193 resep pasien instalasi gawat darurat RSU Elim Rantepao sebagai populasi.
Penelitian ini dilakukan terhadap 522 resep pasien instalasi gawat darurat RSU Elim Rantepao sebagai sampel. Penelitian ini dilakukan pada dua fase yaitu fase prescribing dan dispensing. Analisis deskriptif dilakukan pada sampel berupa resep yang telah memenuhi kriteria inklusi dan ekslusi. Sehingga dapat diketahui persentase Medication Error pada Tahap Prescribing yang dapat dilihat pada Tabel 2 dan tahap Dispensing pada Tabel 3.

Tabel 2. Persentase Hasil Penilaian Medication Error pada Tahap Prescribing pada resep IGD RSU Elim Rantepao

\begin{tabular}{lcc}
\multicolumn{1}{c}{$\begin{array}{c}\text { PARAMETER YANG } \\
\text { DINILAI }\end{array}$} & $\begin{array}{c}\text { JUMLAH } \\
\text { KEJADIAN }\end{array}$ & $(\boldsymbol{\%})$ \\
\hline Tulisan resep tidak terbaca & 0 & 0 \\
\hline $\begin{array}{l}\text { Tidak ada nama dokter } \\
\text { penulis resep }\end{array}$ & 48 & 9,19 \\
$\begin{array}{l}\text { Tidak ada nomor rekam } \\
\text { medik }\end{array}$ & 32 & 6,13 \\
\hline Tidak ada paraf dokter & 520 & 99,61 \\
\hline Nama pasien tidak jelas & 3 & 0,57 \\
\hline Tidak ada usia & 36 & 6,89 \\
\hline $\begin{array}{l}\text { Tidak ada } \\
\text { konsentrasi/dosis sediaan }\end{array}$ & 14 & 2,68 \\
\hline Tidak ada jumlah obat & 0 & 0 \\
\hline Tidak ada aturan pakai & 0 & 0 \\
\hline Tidak ada bentuk sediaan & 272 & 52,10 \\
\hline $\begin{array}{l}\text { Tidak ada tanggal } \\
\text { pembuatan resep }\end{array}$ & 9 & 1,72 \\
\hline
\end{tabular}

Berdasarkan tabel diatas, menunjukkan bahwa pada tahap prescribing yang berpotensi menimbulkan medication error yang terjadi karena tidak ada nama dokter penulis resep 9,19\%, tidak ada nomor rekam medik $6,13 \%$, tidak ada paraf dokter $99,61 \%$, nama pasien tidak jelas $0,57 \%$, tidak ada usia pasien 6,89\%, tidak ada konsentrasi/dosis sediaan 2,68\%, tidak ada bentuk sediaan 52,10 \%, dan tidak ada 
tanggal pembuatan resep $1,72 \%$. Sedangkan, terdapat 3 indikator yang mempunyai tingkat kejadian sebanyak 0\%. Indikatorindikator tersebut ialah tulisan resep tidak terbaca, tidak ada jumlah obat, dan tidak ada aturan pakai.

Tabel 3. Persentase Hasil Penilaian Medication Error pada Tahap Dispensing pada resep IGD RSU Elim Rantepao

\begin{tabular}{|c|c|c|}
\hline $\begin{array}{c}\text { PARAMETER YANG } \\
\text { DINILAI }\end{array}$ & $\begin{array}{c}\text { JUMLAH } \\
\text { KEJADIAN }\end{array}$ & $(\%)$ \\
\hline Salah pengambilan obat & 2 & 0,38 \\
\hline Salah menyerahkan obat & 0 & 0 \\
\hline $\begin{array}{l}\text { Pemberian etiket yang salah } \\
\text { atau tidak lengkap }\end{array}$ & 0 & 0 \\
\hline Pemberian obat diluar instruksi & 0 & 0 \\
\hline Obat yang diserahkan kurang & 1 & 0,19 \\
\hline Obat kadaluarsa/ sudah rusak & 0 & 0 \\
\hline $\begin{array}{l}\text { Berdasarkan } \\
\text { menunjukkan bahwa pada } \\
\text { yang berpotensi menimb } \\
\text { error yang terjadi karena s } \\
\text { obat } 0,38 \% \text { dan obat a } \\
0,19 \% \text {. Sedangkan terdapa } \\
\text { mempunyai tingkat kejadi } \\
\text { Indikator-indikator terseb } \\
\text { menyerahkan obat pada p } \\
\text { etiket yang salah atau } \\
\text { pemberian obat diluar in } \\
\text { yang diserahkan kurang. }\end{array}$ & $\begin{array}{l}\text { tabel di } \\
\text { tahap dispen } \\
\text { ulkan medicc } \\
\text { alah pengamb } \\
\text { da yang ku } \\
\text { t } 4 \text { indikator } \\
\text { an sebanyak } \\
\text { out ialah s } \\
\text { asien, pembe } \\
\text { tidak leng } \\
\text { struksi, dan }\end{array}$ & $\begin{array}{l}\text { Itas, } \\
\text { sing } \\
\text { tion } \\
\text { ilan } \\
\text { ang } \\
\text { ang } \\
0 \% \text {. } \\
\text { alah } \\
\text { rian } \\
\text { xap, } \\
\text { obat }\end{array}$ \\
\hline
\end{tabular}

Pembahasan

Medication error pada fase prescribing

Sampel yang diperoleh selama penelitian adalah sebanyak 522 resep. Penelitian yang dilakukan pada resep pasien IGD di RSU Elim Rantepao pada fase prescribing memiliki 11 indikator sebagai parameter penilaian. Parameter peniliaian tersebut yaitu tulisan resep tidak terbaca, tidak ada nama dokter penulis resep, tidak ada nomor rekam medik, tidak ada paraf dokter, nama pasien tidak jelas, tidak ada usia, tidak ada konsentrasi/dosis sediaan, tidak ada jumlah obat, tidak ada aturan pakai, tidak ada bentuk sediaan dan tidak ada tanggal pembuatan resep.

Penelitian ini menunjukkan ada 9,19\% resep yang tidak terdapat nama dokter penulis resep. Hal ini dikarenakan dokter cenderung lupa menulis namanya di resep. Menurut Peraturan Menteri Kesehatan (2014), persyaratan administrasi resep wajib mencantumkan nama dokter, nomor SIP dokter, dan paraf dokter penulis resep. Tercantumnya nama dokter di resep sangat diperlukan pasien apabila terjadi hal-hal yang tidak dinginkan dalam pengobatannya. Selain itu, tercantumnya nama dokter di resep dapat memudahkan apoteker untuk menghubungi dokter yang bersangkutan apabila ada obat yang kosong dan ingin diganti dengan obat yang lain.

Tidak ada nomor rekam medik dapat menyebabkan medication error karena hal ini terkait dengan data pasien. Terdapat 6,13 $\%$ resep yang tidak tercantum nomor rekam medik pasien. Nomor rekam medik dapat menjadi pembeda apabila ada nama pasien yang sama sehingga kesalahan pemberian obat dapat terhindarkan. Melalui rekam medik juga apoteker dapat mengetahui ataupun mengisi informasi riwayat pengobatan pasien yang tentunya akan berguna jika ada pemeriksaan lanjutan. Paraf dokter dalam resep merupakan suatu bukti bahwa yang tertulis dalam resep adalah sah (Susanti, 2013). Hal ini dilakukan untuk 
menghindari penyalahgunaan obat di masyarakat (terlebih untuk resep narkotika dan psikotropika). Hasil penelitian ini menunjukkan terdapat $99,61 \%$ resep tanpa paraf dokter.

Nama pasien tidak jelas juga dapat menyebabkan medication error karena identitas ataupun obat yang akan diberikan bisa saja tertukar. Selain itu, nama pasien yang tidak jelas cenderung menimbulkan kesalahan penyebutan nama saat pasien dipanggil untuk pengambilan obat. Dalam penelitian ini terdapat $0,57 \%$ resep yang nama pasiennya tidak jelas.

Tidak ada usia ataupun tanggal lahir dapat berakibat fatal terutama pada resep bayi, balita, dan lansia. Usia pasien disini penting untuk mempertimbangkan dosis sediaan yang akan diberikan. Usia juga diperlukan dalam perhitungan dosis untuk peracikan obat. Untuk pasien lanjut usia yang fungsi fisiologi tubuhnya mulai menurun, pemberian dosis harus lebih kecil dari dosis maksimum (Syamsuni, 2006). Dalam penelitian ini terdapat $6,89 \%$ resep yang tidak ada usia pasien.

Dalam penelitian ini terdapat $2,68 \%$ resep yang tida ada konsentrasi/dosis sediaan obatnya. Tidak ada konsentrasi / dosis sediaan juga perlu diperhatikan pada fase prescribing karena ada beberapa obat yang memiliki konsentrasi / dosis beragam seperti amlodipine, alupurinol, simvastatin, dan lain sebagainya. Pemberian obat-obat tersebut harus diperhatikan agar tidak menimbulkan kesalahan.

Tidak adanya bentuk sediaan pada resep dapat merugikan pasien karena pemilihan bentuk sediaan ini disesuaikan dengan kondisi tubuh dan kenyamanan pasien. Tidak adanya bentuk sediaan juga dapat membingungkan petugas Instalasi Farmasi yang menyiapkan obat karena harus mengonfirmasi dengan dokter penulis resep kembali sehingga dapat menyebabkan keterlambatan pelayanan. Terdapat $52,10 \%$ resep yang diteliti tidak ada bentuk sediaan dan hal ini dapat memicu terjadinya medication error.

Tanggal pembuatan resep penting untuk dicantumkan hal ini dikarenakan ada beberapa sediaan yang stabilitasnya dapat berubah dalam proses penyiapan. Salah satu contohnya yaitu racikan sediaan puyer perlu dicantumkan beyond use date agar pasien memahami kapan sebaiknya puyer tersebut seharusnya tidak boleh digunakan lagi hal ini guna meningkatkan keamanan pasien. Beyond use date (BUD) dalam USP didefinisikan sebagai tanggal dan waktu setelah persiapan dimana sediaan tidak boleh digunakan atau dipindahkan. Hasil penelitian menunjukkan bahwa terdapat $1,72 \%$ resep yang tidak memuat tanggal pembuatan resep.

\section{Medication error pada fase dispensing}

Penelitian yang dilakukan pada resep pasien IGD di RSU Elim Rantepao pada fase dispensing memiliki 6 indikator sebagai parameter penilaian. Parameter peniliaian tersebut yaitu salah pengambilan obat, salah menyerahkan obat pada pasien, pemberian etiket yang salah atau tidak lengkap, pemberian obat diluar instruksi, obat yang ada kurang, dan obat kadaluarsa/sudah rusak.

Kesalahan dalam pengambilan obat dapat berakibat buruk bagi pasien karena jika obat yang tertera di resep berbeda 
dengan obat yang diberikan tentu saja akan memberikan efek yang berbeda. Selama penelitian terdapat 2 kasus salah pengembilan obat, namun obat tersebut belum sampai ke tangan pasien. Minimnya kesalahan ini terjadi karena proses penyiapan dan penyerahan obat dilakukan oleh orang yang berbeda sehingga meminimalisir kesalahan pemberian obat karena dilakukan pengecekan ulang oleh orang yang berbeda. Penyusunan obat di instalasi farmasi RSU Elim Rantepao menggunakan susunan alfabetis sehingga memudahkan dalam pengambilan obat. Obat-obat yang memiliki nama ataupun tampilan yang mirip diberi tanda LASA agar kesalahan pengambilan obat dapat dicegah. Hasil penelitian di salah satu Rumah Sakit Jakarta Utara menunjukkan bahwa kesalahan pengambilan obat disebabkan karena obat memiliki bentuk dan nama yang serupa (LASA). Selain itu, banyaknya resep yang masuk juga menjadi salah satu alasan kesalahan dalam pengambilan obat (Pernama, 2017).

Selama penelitian terdapat satu kasus kesalahan obat yang diserahkan kurang namun hal itu terjadi sebelum obat berada di tangan pasien. Pada fase dispensing tidak ditemukan adanya obat yang kadaluarsa maupun rusak. Hal ini dikarenakan penyimpanan obat di Instalasi Farmasi RSU Elim Rantepao menggunakan metode FEFO (First Expired First Out) sehingga dapat mengantisipasi terjadinya penyerahan obat yang kadaluarsa maupun rusak. Hal ini sejalan dengan penelitian yang dilakukan di RSUP Fatmawati Jakarta yang menunjukkan bahwa tidak ditemukannya obat yang rusak maupun kadaluarsa dikarenakan penyimpanan obat di Instalasi disisin berdasarkan sister FIFO (First In First Out) (Susanti, 2013).

Hasil penelitian kejadian medication error pada fase dispensing di Instalasi Gawat Darurat RSU Elim Rantepao hanya sedikit dibanding dengan kejadian medication error fase dispensing. Hal ini menunjukkan proses penyiapan dan penyerahan obat di RSU Elim Rantepao sudah baik. Selain itu, RSU Elim Rantepao telah memiliki Tim Keselamatan Pasien yang akan mengawasi dan mengontrol kejadian yang tidak diinginkan salah satunya medication error.

\section{KESIMPULAN}

Medication error yang terjadi pada tahap prescribing yaitu tidak ada nama dokter penulis resep 9,19\%, tidak ada nomor rekam medik 6,13\%, tidak ada paraf dokter 99,61\%, nama pasien tidak jelas 0,57\%, tidak ada usia pasien $6,89 \%$, tidak ada konsentrasi/dosis sediaan $2,68 \%$, tidak ada bentuk sediaan 52,10 \%, dan tidak ada tanggal pembuatan resep $1,72 \%$. Persentase medication error pada fase dispensing yaitu salah pengambilan obat $0,38 \%$ dan obat ada yang kurang 0,19\%.

\section{SARAN}

Semua tenaga kesehata perlu untuk lebih memperhatikan hal-hal yang berpotensi untuk menimbulkan medication error pada tahap prescribing dan dispensing khususnya pada pasien-pasien Instalasi Gawat Darurat. Selain itu, perlu dilakukan penelitian tentang medication error pada fase yang lain. 


\section{DAFTAR PUSTAKA}

Departemen Kesehatan RI. 2008. Tanggungjawab Apoteker Terhadap Keselamatan Pasien (Patient safety). Jakarta.

Mashuda, A. 2011. Pedoman Cara Pelayanan Kefarmasian yang Baik (CPFB) / Good Pharmacy Practice $(G P P)$. Kementrian Kesehatan Republik Indonesia dan Pengurus Pusat Ikatan Apoteker Indonesia, Jakarta.

Patanwala, AE., Warholak T.L., Sanders A.B., Erstad B.L. 2010. A Prospective Observational Study of Medication Errors in A Tertiary Care Emergency Department. Ann Emerg Med. 55(6):522-6.

Peraturan Menteri Kesehatan Nomor 58 Tahun 2014 Tentang Standar Pelayanan Kefarmasian Di Rumah Sakit. Kementerian Kesehatan RI, Jakarta.

Peraturan Pemerintah No. 51 Tahun 2009 Tentang Pekerjaan Kefarmasian. Jakarta.

Pernama, A.M. 2017. Evaluasi Medication Error pada Resep Pasien Diabetes Mellitus Tipe II Ditinjau dari Fase Prescribing, Transcribing, dan Dispensing di Instalasi Rawat Jalan Salah Satu Rumah Sakit Jakarta Utara [skripsi], Fakultas Kedokteran dan Ilmu Kesehatan, Universitas Islam Negeri Syarif Hidayatullah, Jakarta.

Sibagariang, E. 2010. Buku Penelitian Untuk Mahasiswa Diploma Kesehatan. Trans Info Media, Jakarta.

Susanti, I. 2013. Identifikasi Medication Error pada Fase Prescribing,
Transcribing, dan Dispensing Di Depo Farmasi Rawat Inap Penyakit Dalam Gedung Teratai Instalasi Farmasi RSU Fatmawati [skripsi], Fakultas Kedokteran dan Ilmu Kesehatan, Universitas Islam Negeri Syarif Hidayatullah, Jakarta.

Syamsuni. 2006. Ilmu Resep. EGC, Jakarta.

Tajuddin, R.S., Sudirman, I., Maidin, A. 2012. Faktor Penyebab Medication Error di Instalasi Rawat Darurat. Jurnal Manajemen Pelayanan Kesehatan. 15 (4) : 182-187

Teixeira TCA, Cassiani SHB. Root cause analysis: evaluation of medication error at a university hospital. 2010. Rev Esc Enferm USP. 44 (1): 137-44

United States Pharmacopeia 29. Chapter 795: Pharmaceutical compounding nonsterile preparations. Twinbrook Parkway, United States 